\title{
A Detailed Protocol for Subcellular RNA Sequencing (subRNA-seq)
}

\author{
Andreas Mayer ${ }^{1}$ and L. Stirling Churchman ${ }^{2}$ \\ ${ }^{1}$ Max Planck Institute for Molecular Genetics, Berlin, Germany \\ ${ }^{2}$ Department of Genetics, Harvard Medical School, Boston, Massachusetts
}

In eukaryotic cells, RNAs at various maturation and processing levels are distributed across cellular compartments. The standard approach to determine transcript abundance and identity in vivo is RNA sequencing (RNA-seq). RNA-seq relies on RNA isolation from whole-cell lysates and thus mainly captures fully processed, stable, and more abundant cytoplasmic RNAs over nascent, unstable, and nuclear RNAs. Here, we provide a step-by-step protocol for subcellular RNA-seq (subRNA-seq). subRNA-seq allows the quantitative measurement of RNA polymerase II-generated RNAs from the chromatin, nucleoplasm, and cytoplasm of mammalian cells. This approach relies on cell fractionation prior to RNA isolation and sequencing library preparation. High-throughput sequencing of the subcellular RNAs can then be used to reveal the identity, abundance, and subcellular distribution of transcripts, thus providing insights into RNA processing and maturation. Deep sequencing of the chromatin-associated RNAs further offers the opportunity to study nascent RNAs. Subcellular RNA-seq libraries are obtained within 5 days. (c) 2017 by John Wiley \& Sons, Inc.

Keywords: Cell fractionation • subcellular RNA-seq • nascent RNA • RNA polymerase II (Pol II) • transcription • next-generation sequencing • RNA processing

\section{How to cite this article:}

Mayer, A., \& Churchman, L. S. (2017). A Detailed protocol for subcellular RNA sequencing (subRNA-seq). Current Protocols in Molecular Biology, 120, 4.29.1-4.29.18. doi: 10.1002/cpmb.44

\section{INTRODUCTION}

Eukaryotic genomes are pervasively transcribed by RNA polymerase II (Pol II), giving rise to all messenger RNAs and a large set of non-coding RNAs (Djebali et al., 2013; Jensen et al., 2013; Pelechano \& Steinmetz, 2013). Nascent RNA is synthesized in a chromatin environment by stable Pol II transcription complexes (Jonkers \& Lis, 2015; Venkatesh \& Workman, 2015). At the poly-adenylation (pA) site, the nascent transcript is cleaved and poly-adenylated. The RNA that has been properly processed, as controlled by RNA surveillance mechanisms, is released into the nucleoplasm and further processed before it is exported into the cytoplasm (Kilchert, Wittmann, \& Vasiljeva, 2016). The RNA export is tightly regulated in vivo and involves many export factors (Meinel \& Sträßer, 2015; Oeffinger \& Zenklusen, 2012; Wickramasinghe \& Laskey, 2015). The fully processed messenger RNA (mRNA) serves as a blueprint for protein synthesis in the cytoplasm. Thus, Pol II transcripts at different processing and maturation levels are distributed between distinct cellular compartments, mainly between chromatin (nascent RNA), nucleoplasm (processed and unprocessed RNA), and cytoplasm (mature RNA) (Fig. 4.29.1).

The standard approach to globally measure transcript abundance and identity is RNA preparation coupled with high-throughput sequencing (RNA-seq) (Wang, Gerstein, \& 


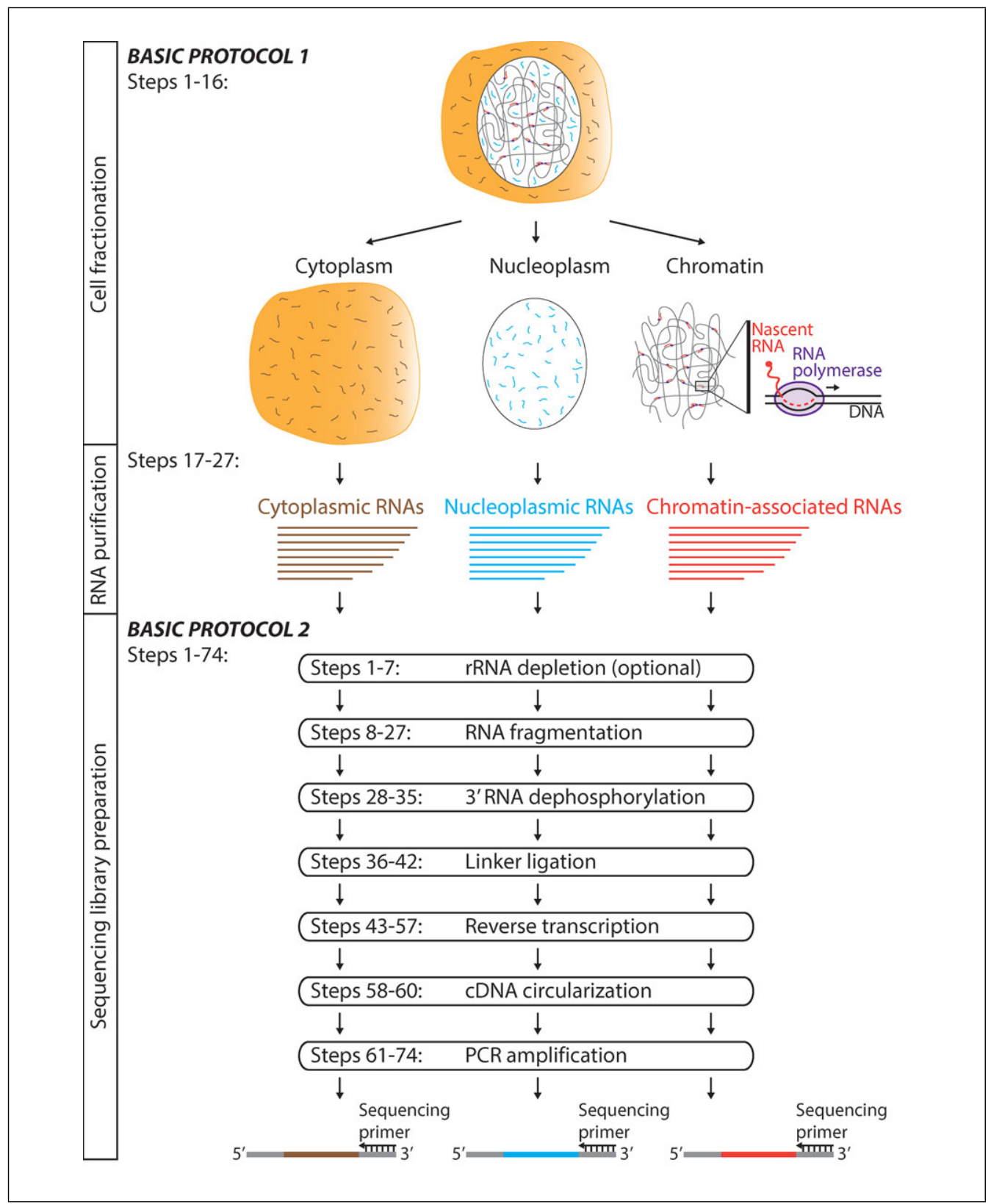

Figure 4.29.1 Schematic overview of the key steps of the subRNA-seq approach.

Snyder, 2009). The standard RNA-seq method relies on the preparation of whole-cell lysates prior to RNA isolation. Therefore, the information about the subcellular location of a given RNA is lost. Furthermore, the generation of whole-cell extracts also results in sequencing libraries that are dominated by fully processed stable RNAs that mainly occur in the cytoplasm. These cytoplasmic RNAs usually complicate the analysis of nascent and unstable transcripts.

To overcome these limitations, new variants of the original RNA-seq method have been recently developed by us and others (Bhatt et al., 2012; Conrad et al., 2014; Ferrari et al., 2013; Mayer et al., 2015; Mondal, Rasmussen, Pandey, Isaksson, \& Kanduri, 2010; Pandya-Jones \& Black, 2009; Tilgner et al., 2012; Weber, Ramachandran, \& Henikoff, 2014; Zaghlool et al., 2013). A commonality among these approaches is that they rely

Subcellular RNA Sequencing (subRNA-seq) on cell and chromatin fractionation prior to RNA purification and sequencing library preparation. 
Here we provide a step-by-step protocol for the genome-wide measurement of transcript abundance and identity in different cellular compartments - chromatin, nucleoplasm, cytoplasm-by subcellular RNA-seq (subRNA-seq). This approach combines effective cell fractionation with robust and efficient sequencing library preparation to reveal the relative abundance and the identity of transcripts in different cellular compartments. subRNA-seq reveals the full spectrum of Pol II-synthesized RNAs, at different processing levels, ranging from unprocessed nascent RNAs to fully processed cytoplasmic RNAs. The approach has been successfully applied to HeLa S3 and HEK293T cells, and will be readily applicable to other mammalian cell types (Mayer et al., 2015). Thus, subRNA-seq represents a powerful genomic tool for the analysis of RNA processing and also provides an opportunity to study nascent RNAs in a broad range of mammalian cell types.

\section{CELL FRACTIONATION AND RNA ISOLATION}

The cell fractionation approach described here is based on protocols that have been developed by us and others (Bhatt et al., 2012; Mayer et al., 2015; Pandya-Jones \& Black, 2009; Wuarin \& Schibler, 1994). It is most similar to the cell fractionation protocol that we have established for human native elongating transcript sequencing (NET-seq; Mayer \& Churchman, 2016; Fig. 4.29.1). Cells are lysed and the cytoplasm is separated from nuclei by centrifugation through a sucrose cushion. The nuclei pellet is washed to remove cytoplasmic remnants prior to chromatin fractionation. The chromatin is separated from the nucleoplasm in the presence of urea, the nonionic detergent Nonidet P-40 (NP-40), and $\mathrm{NaCl}$, as originally described by the Schibler lab (Wuarin \& Schibler, 1994). Next, the RNA is prepared in parallel from the chromatin, nucleoplasmic, and cytoplasmic fractions. Remaining DNA is removed by a standard DNase I digest.

Cell fractionation is performed in the presence of the Pol II transcription inhibitor $\alpha$ amanitin (Brueckner \& Cramer, 2008; Lindell, Weinberg, Morris, Roeder, \& Rutter, 1970) and RNase inhibitors to avoid run-off transcription and RNA degradation during sample processing, respectively.

We recommend monitoring the success of the cell fractionation experiment by western blot analysis (Fig. 4.29.2A) using antibodies against subcellular markers. This is especially true when the cell fractionation approach is applied to new cell types.

\section{Materials}

Cultured mammalian cells: $1 \times 10^{7}$ cells per experiment

Phosphate-buffered saline (PBS; Life Technologies, cat. no. 10010-023)

Cytoplasmic lysis buffer (see recipe)

Sucrose buffer (see recipe)

Nuclei wash buffer (see recipe)

Glycerol buffer (see recipe)

Nuclei lysis buffer (see recipe)

TRI reagent (MRC, cat. no. TR 118)

Chloroform (Sigma, cat. no. 288306)

RLT buffer (Qiagen, cat. no. 79216)

$100 \%$ (v/v) ethanol (VWR, cat. no. V1016)

RNeasy Mini Kit (Qiagen, cat. no.74104)

RNase-Free DNase Set (Qiagen, cat. no. 79254)

RNase/DNase-free $\mathrm{H}_{2} \mathrm{O}$ (Life Technologies, cat. no. 10977-015)

Antibodies (optional; for monitoring the experiment by western blotting):

Pol II Ser-2P antibody (3E8; Active Motif, cat. no. 61083)

Histone 2B antibody (FL-126; Santa Cruz Biotechnology, cat. no. sc-10808)
BASIC

PROTOCOL 1

Preparation and Analysis of RNA

4.29.3

Supplement 120 


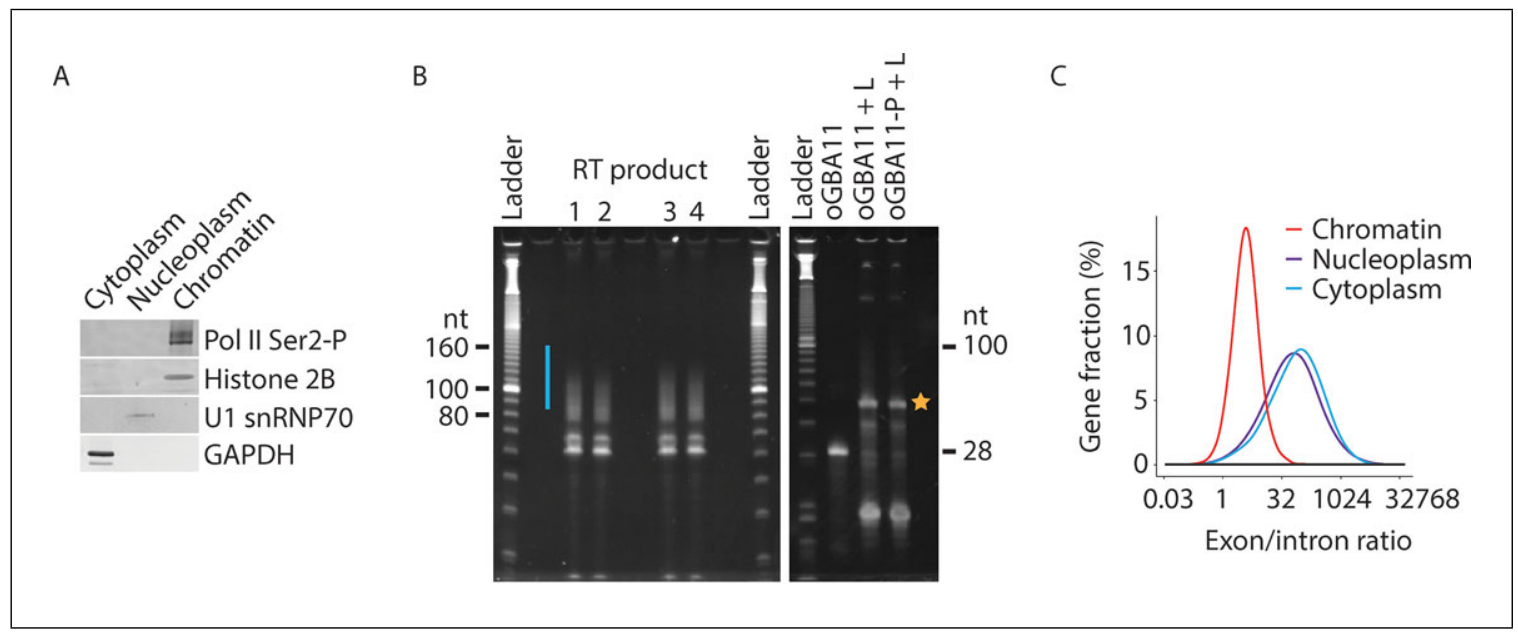

Figure 4.29.2 Key quality controls and expected results from subRNA-seq experiments. (A) Representative western blot of subcellular fractions. The different cellular fractions obtained from HeLa S3 cells were probed against transcribing Pol II (Pol II Ser2-P; 3E8 antibody), the chromatin marker Histone 2B (FL-126 antibody), the nucleoplasmic marker U1 snRNP70 (C-18 antibody), and the cytoplasmic marker GAPDH (6C5 antibody). The volumes of the different cellular fractions have been adjusted so that the western blot signals can be compared between the fractions. This figure was modified from Mayer et al. (2015). (B) Representative gels showing the product of the reverse transcription (RT) of the samples (left panel) and of the oGAB11 controls (right panel). The region that is excised from the gel is indicated by a blue bar or yellow star for the samples and the oGAB11 controls, respectively. (C) Distributions of the size-normalized ratio of subRNA-seq reads that map to exons versus introns for each gene. subRNA-seq libraries were generated from HeLa S3 cells. This figure was adapted from (Mayer et al., 2015).

U1 snRNP70 antibody(C-18; Santa Cruz Biotechnology, cat. no. sc-9571)

GAPDH antibody (6C5; Life Technologies, cat. no. AM4300)

Cell scrapers
Refrigerated centrifuge

Additional reagents and equipment for basic cell culture techniques including counting cells (Phelan \& May, 2017) and for western blotting (immunoblotting; UNIT 10.8, Ni., Xu, and Gallagher, 2016)

\section{Cell fractionation}

All experimental steps of the cell fractionation are performed on ice or at $4{ }^{\circ} \mathrm{C}$. Pre-cooled buffers are used.

1. Use $1 \times 10^{7}$ cells as an input per experiment.

The amount of input refers to HeLa S3 and HEK293T cells. Although we expect that the number of cells required for a successful subRNA-seq experiment should be similar for other mammalian cell types, in some cases protocol adjustments might be necessary, as described in the Commentary section. We recommend determining the number of cells by cell counting (APPENDIX 3F; Phelan \& May, 2017).

2. Wash cells twice, each time with $10 \mathrm{ml}$ PBS.

3. Scrape cells into $9 \mathrm{ml}$ PBS.

This experimental step refers to cells that grow adherently or semi-adherently.

4. Centrifuge $2 \mathrm{~min}$ at $500 \times g, 4^{\circ} \mathrm{C}$. Discard supernatant.

Subcellular RNA Sequencing (subRNA-seq)

5. Resuspend cell pellets in $200 \mu$ l cytoplasmic lysis buffer using pipet tips that have been widened by cutting the narrow end off.

6. Incubate on ice for $5 \mathrm{~min}$.

\subsection{4}


7. Layer the cell lysate onto $500 \mu 1$ sucrose buffer using pipet tips that have been widened by cutting the narrow end off.

8. Centrifuge $10 \mathrm{~min}$ at $16,000 \times g, 4^{\circ} \mathrm{C}$.

9. Transfer the supernatant to a new tube and store on ice until further processed (see step 23).

The supernatant represents the cytoplasmic fraction.

10. Wash nuclei pellet with $800 \mu \mathrm{l}$ nuclei wash buffer.

11. Centrifuge $1 \mathrm{~min}$ at $1,150 \times g, 4^{\circ} \mathrm{C}$. Discard supernatant.

12. Cut tips and gently resuspend nuclei in $200 \mu 1$ glycerol buffer.

13. Add $200 \mu 1$ nuclei lysis buffer.

14. Mix by pulse vortexing and incubate on ice for $2 \mathrm{~min}$.

15. Centrifuge $2 \mathrm{~min}$ at $18,500 \times g, 4^{\circ} \mathrm{C}$.

16. Transfer the supernatant to a new tube and store on ice until further processed (see step 23), and also keep the pellet.

The supernatant and pellet represent the nucleoplasmic and chromatin fraction, respectively.

\section{Isolation of chromatin-associated, nucleoplasmic, and cytoplasmic RNAs}

\section{Chromatin RNA}

17. Add $50 \mu \mathrm{l}$ pre-cooled PBS to the chromatin pellet (from step 16) and resuspend by pipetting.

18. Add $500 \mu \mathrm{l}$ TRI reagent and resuspend the pellet by vortexing.

19. Add $100 \mu \mathrm{l}$ chloroform, vortex, and incubate at room temperature for $5 \mathrm{~min}$.

20. Centrifuge $15 \mathrm{~min}$ at $16,000 \times g, 4^{\circ} \mathrm{C}$.

21. Transfer the upper aqueous layer to a new tube, add 3.5 sample volumes of RLT buffer, and mix.

22. Add 2.5 times the initial sample volume (before the RLT buffer was added) of ice-cold 100\% (v/v) ethanol and mix. Proceed with step 25.

Cytoplasmic and nucleoplasmic RNA

23. Add 3.5 sample volumes of RLT buffer and mix.

24. Add 2.5 times the initial sample volume (before the RLT buffer was added) of ice-cold 100\% (v/v) ethanol and mix. Proceed with step 25.

Chromatin, cytoplasmic, and nucleoplasmic RNA

25. Follow clean up protocol of the RNeasy Kit (Qiagen) according to manufacturer's instructions.

26. Perform an on-column DNase I digest (using Qiagen RNase-free DNase set) according to manufacturer's instructions.

27. Elute in $50 \mu \mathrm{l}$ RNase/DNase-free $\mathrm{H}_{2} \mathrm{O}$.

Proceed with the sequencing library preparation immediately or store the RNA at $-80^{\circ} \mathrm{C}$. 
The RNA concentration as determined by NanoDrop spectrophotometer measurement for the cytoplasmic, nucleoplasmic, and chromatin fractions is typically 3000 to 4000, 600 to 700 , and 400 to $500 \mathrm{ng} / \mu \mathrm{l}$, respectively.

BASIC PROTOCOL 2
Subcellular RNA Sequencing (subRNA-seq)

\section{SEQUENCING LIBRARY PREPARATION}

The second part of the subRNA-seq approach exploits an efficient sequencing library preparation method. The library preparation is based on protocols that we developed for the human NET-seq approach (Mayer \& Churchman, 2016; Mayer et al., 2015) and is also related to generation of libraries used for yeast NET-seq (Churchman and Weissman, 2012a,b) and ribosome profiling (Ingolia, Brar, Rouskin, McGeachy, \& Weissman, 2012).

Here, the chromatin, nucleoplasmic, and cytoplasmic RNAs obtained in Basic Protocol 1 , steps 1 to 27, are converted into DNA sequencing libraries. This is accomplished by the following major steps: (1) ribosomal RNAs (rRNAs) are depleted from the subcellular RNAs using a commercially available removal kit; (2) RNA is fragmented by partial alkaline hydrolysis; (3) 3'-phosphate groups are removed from the fragmented RNA; (4) a barcoded DNA linker is ligated to the $3^{\prime}$-ends of the RNA; (5) RNA is converted into cDNA; (6) circularized; and (7) amplified using a limited number of PCR cycles (Fig. 4.29.1).

Each of these key steps has been optimized to work at a high efficiency, and success is monitored by quality controls. If the library passes all quality checks, it is subjected to an Illumina high-throughput sequencing platform such as MiSeq, HighSeq, or NextSeq.

Although we describe a NET-seq-based library preparation method here, we expect that our cell fractionation and RNA isolation approach (Basic Protocol 1) can also be combined with alternative library preparation protocols to obtain sequencing libraries.

\section{Materials}

RNA (Basic Protocol 1)

Ribo-Zero rRNA Removal Kit (Epicentre, cat. no. MRZH116)

$80 \%$ (v/v) ethanol (VWR, cat. no. V1016)

RNase/DNase-free $\mathrm{H}_{2} \mathrm{O}$ (Life Technologies, cat. no. 10977-015)

50\% PEG8000 (supplied with the truncated T4 RNA Ligase 2; NEB, cat. no. M0242S)

Dimethylsulfoxide (DMSO; Sigma, cat. no. D8418)

T4 RNA Ligase buffer, 10× (supplied with the truncated T4 RNA Ligase 2; NEB, cat. no. M0242S)

EDTA (0.5 M; Life Technologies, cat. no. AM9260G)

Alkaline fragmentation solution (see recipe)

RNA precipitation solution (see recipe)

RNA control ladder (0.1 to $2 \mathrm{~kb}$; Life Technologies, cat. no. 15623-100)

oGAB11 control (Table 4.29.1)

$2 \times$ TBU denaturing loading buffer (Life Technologies, cat. no. LC6876)

TBE-urea gels, 15\% (w/v) (Life Technologies, cat. no. EC68852BOX)

Gel staining solution (see recipe)

GlycoBlue (15 mg/ml; Life Technologies, cat. no. AM9515)

Sodium acetate, RNase-free (3 M, pH 5.5; Life Technologies, cat. no. AM9740)

Isopropanol (Sigma, cat. no. 278475)

T4 PNK buffer, $10 \times$ (supplied with T4 Polynucleotide Kinase, NEB, cat. no. M0201S)

SUPERase.In (20 U/ $\mu$; Life Technologies, cat. no. AM2696)

T4 Polynucleotide Kinase (10,000 U/ml; NEB, cat. no. M0201S)

DNA linker-1 (Table 4.29.1) 
Table 4.29.1 DNA and RNA Oligos Required for the Preparation of Subcellular RNA-Seq Libraries

\section{DNA oligos}

Linker-1 $1^{a, b, c}$

oLSC007 (RT primer) ${ }^{d, e}$

oNTI231 (reverse primer)

oLSC006 (sequencing primer)

RNA oligos

oGAB11 (control oligo)

oGAB11-P $f$
15rApp/CTGTAGGCACCATCAAT/3ddC

15Phos/ATCTCGTATGCCGTCTTCTGCTTG/iSp18/CA CTCA/iSp18/TCCGACGATCATTGATGGTGCCTACAG

CAAGCAGAAGACGGCATACGA

TCCGACGATCATTGATGGTGCCTACAG

agucacuuagcgauguacacugacugug

agucacuuagcgauguacacugacugug/3Phos/

${ }^{a}$ 5rApp: $5^{\prime}$-riboadenylate.

b3ddC: 3'-dideoxycytidine.

${ }^{c}$ Commercially available from Integrated DNA Technologies.

'5Phos: 5'-phosphate.

$e_{i S p} 18$ : internal 18-atom hexa-ethylenglycol spacer.

$f_{3 \text { Phos: }} 3^{\prime}$-phosphate.

T4 RNA Ligase 2, truncated (NEB, cat. no. M0242S)

$5 \times$ First-Strand Buffer (part of SuperScript III First-Strand Synthesis System; Life

Technologies, cat. no. 18080-051)

dNTP mix (10 mM each dNTP; Life Technologies, cat. no. 18427-013)

DTT (0.1 M; part of the SuperScript III First-Strand Synthesis System, Life

Technologies, cat. no. 18080-051)

SUPERase.IN/DTT mix (see recipe)

200 U/ $\mu 1$ SuperScript III First-Strand Synthesis System (Life Technologies, cat. no. 18080-051)

$1 \mathrm{~N} \mathrm{NaOH}$

$1 \mathrm{~N} \mathrm{HCl}$

DNA control ladder (10 bp; Life Technologies, cat. no. 10821-015)

TBE-urea gels, $10 \%$ (w/v) (Life Technologies, cat. no. EC68752BOX)

TBE buffer, 10× (Life Technologies, cat. no. 15581-044)

Gel staining solution (see recipe)

$5 \mathrm{M} \mathrm{NaCl}$

$10 \mathrm{mM}$ Tris $\cdot \mathrm{Cl}, \mathrm{pH} 8.0$ (APPENDIX 2)

CircLigase reaction buffer, $10 \times$ (part of CircLigase ssDNA Ligase, Epicentre, cat. no. CL4111K)

ATP, $1 \mathrm{mM}$ (supplied with CircLigase ssDNA Ligase, Epicentre, cat. no. CL4111K)

$\mathrm{MnCl}_{2}, 50 \mathrm{mM}$ (supplied with CircLigase ssDNA Ligase, Epicentre, cat. no. CL4111K)

CircLigase ssDNA Ligase (100 U/ $\mu$; Epicentre, cat. no. CL4111K)

Phusion HF Buffer, $5 \times$ (supplied with Phusion High-Fidelity DNA Polymerase, NEB, cat. no. M0530S)

Illumina index primer (for example Barcode 4 Illumina index primer:

AATGATACGGCGACCACCGAGATCTACACGATCGGAAGAGCA-

CACGTCTGAACTCCAGTCACTGACCATCCGACGATCATTGATGG)

Phusion DNA Polymerase $(2,000 \mathrm{U} / \mathrm{ml}$; NEB, cat. no. M0530S)

$6 \times$ DNA loading dye (UNIT 10.2A; Gallagher, 2012)

TBE gels, 8\% (w/v) (Life Technologies, cat. no. EC62152BOX)

DNA soaking buffer (see recipe)

Qubit dsDNA HS Assay Kit (Life Technologies, cat. no. Q32851)

High Sensitivity Bioanalyzer DNA Analysis Kit (Agilent Technologies, cat. no. 5067-4626)

Preparation and Analysis of RNA 
Refrigerated centrifuge

Thermomixer

Thermal cycler

Blue or UV light source

Scalpels (Electron Microscopy Sciences, cat. no. 72042-11)

$0.5-\mathrm{ml}$ and $1.5-\mathrm{ml} \mathrm{RNase} / \mathrm{DNase}-$ free non-stick microcentrifuge tubes

20-G needle (BD, cat. no. 305175)

Microcentrifuge tube filter: Costar Spin-X centrifuge tube filters (Sigma, cat. no.

CLS8162-96EA)

0.2-ml PCR tubes

Additional reagents and equipment for polyacrylamide gel electrophoresis (UNIT 10.2A; Gallagher, 2012)

\section{rRNA depletion}

In order to increase the fraction of informational sequencing reads that originate from Pol II-synthesized transcripts, ribosomal RNAs are depleted. The rRNA depletion is optional.

1. Use $20 \mu \mathrm{g}$ of RNA as input per depletion.

2. Apply the Ribo-Zero rRNA Removal Kit and follow the manufacturer's instructions to deplete the ribosomal RNA.

3. Following the RNA precipitation (as described in the manufacturer's instructions), centrifuge $30 \mathrm{~min}$ at $20,000 \times \mathrm{g}, 4^{\circ} \mathrm{C}$. Discard supernatant.

4. Wash RNA pellet with $750 \mu 1$ pre-cooled $80 \%$ (v/v) ethanol, microcentrifuge briefly to bring liquid to bottom of tube, and discard supernatant.

5. Repeat ethanol wash (step 4) one more time.

6. Air-dry pellet at room temperature for approximately $10 \mathrm{~min}$.

7. Resuspend the RNA pellet in $10 \mu \mathrm{RNase} / \mathrm{DNase}$-free $\mathrm{H}_{2} \mathrm{O}$.

Proceed with RNA fragmentation immediately or store at $-80^{\circ} \mathrm{C}$.

\section{RNA fragmentation}

RNA fragmentation is performed by partial alkaline hydrolysis as described in detail in the human and yeast NET-seq protocols (Churchman \& Weissman, 2012b; Mayer \& Churchman, 2016). The fragmentation time needs to be adjusted for new batches of alkaline fragmentation solution. The length of the majority of the fragmented RNA should be in the range that is excised from the polyacrylamide gel, as described below.

8. Denature $\geq 3 \mu \mathrm{g}$ of rRNA-depleted RNA for $2 \mathrm{~min}$ at $80^{\circ} \mathrm{C}$ and microcentrifuge briefly to bring liquid to bottom of tube.

9. Prepare the fragmentation mix as follows:

Subcellular RNA Sequencing (subRNA-seq)

$\begin{array}{lll}\text { Component } & \text { Amount per reaction }(\mu \mathrm{l}) & \text { Final } \\ \text { PEG8000 }(50 \% \mathrm{v} / \mathrm{v}) & 8.0 & 20 \%(\mathrm{v} / \mathrm{v}) \\ \text { DMSO } & 2.0 & 10 \%(\mathrm{v} / \mathrm{v}) \\ \text { T4 RNA Ligase buffer }(10 \times) & 2.0 & 1 \times \\ \text { EDTA }(0.5 \mathrm{M}) & 0.7 & 17.5 \mathrm{mM} \\ \text { RNA }(1 \mu \mathrm{g} / \mu \mathrm{l} \text {; from step 8) } & 1.0 & 1 \mu \mathrm{g} \\ \text { RNase/DNase-free } \mathrm{H}_{2} \mathrm{O} & 6.3 & \end{array}$

Prepare three fragmentation mixes per sample. 
10. Add $20 \mu \mathrm{l}$ of $2 \times$ alkaline fragmentation solution to each sample and mix.

11. Fragment RNA for the adjusted time at $95^{\circ} \mathrm{C}$ in a thermal cycler. Place immediately on ice.

The fragmentation time needs to be adjusted for each new batch of alkaline fragmentation solution. Fragmentation times between 10 to 40 min should be tested. The size of most RNA fragments should be between 30 and $100 \mathrm{nt}$.

12. Add sample to $562 \mu 1$ of RNA precipitation solution and mix. Add $750 \mu 1$ isopropanol and mix. Precipitate the fragmented RNA for $\geq 1 \mathrm{hr}$ at $-80^{\circ} \mathrm{C}$.

13. Centrifuge $30 \mathrm{~min}$ at $20,000 \times g, 4^{\circ} \mathrm{C}$.

14. Discard supernatant and wash RNA pellet with $750 \mu \mathrm{l}$ of $80 \%$ (v/v) ice-cold ethanol.

15. Air-dry RNA pellet for $10 \mathrm{~min}$ at room temperature

16. Resuspend pellet in $10 \mu \mathrm{l}$ RNase/DNase-free $\mathrm{H}_{2} \mathrm{O}$.

17. Prepare the RNA control ladder and the oGAB11 control (Table 4.29.1). Typically, add $9 \mu \mathrm{l}$ of RNase/DNase-free $\mathrm{H}_{2} \mathrm{O}$ to $1 \mu \mathrm{l}$ RNA control ladder and to $1 \mu \mathrm{l}(10 \mu \mathrm{M})$ oGAB11. Add $10 \mu \mathrm{l}$ of $2 \times$ TBU denaturing loading buffer to the RNA sample, the RNA control ladder, and the oGAB11 control.

18. Denature the RNA sample, the RNA control ladder, and the oGAB11 control for 2 min at $80^{\circ} \mathrm{C}$.

19. Pre-run a $15 \%$ TBE-urea polyacrylamide gel for $15 \mathrm{~min}$ at $200 \mathrm{~V}$ according to the manufacturer's instructions.

20. Load the fragmented RNA sample and the RNA control ladder and run the $15 \%$ TBE-urea gel for $65 \mathrm{~min}$ at $200 \mathrm{~V}$ in $1 \times \mathrm{TBE}$ (also see UNIT 10.2A; Gallagher, 2012).

21. Stain the gel for $5 \mathrm{~min}$ at room temperature in the gel staining solution and visualize the fragmented RNA, the RNA control ladder, and the oGAB11 control under blue or UV light. Excise the fragmented RNA between 30 and $100 \mathrm{nt}$.

\section{Rapid gel extraction of the fragmented RNA}

The rapid gel extraction approach is based on a protocol originally developed by Ingolia et al. (2012) and is described in detail by Mayer \& Churchman (2016).

22. Pierce a $0.5-\mathrm{ml}$ RNase/DNase-free non-stick tube with a $20-\mathrm{G}$ needle and place it inside a 1.5-ml RNase/DNase-free non-stick tube. Transfer the gel slice into the pierced 0.5-ml RNase/DNase-free non-stick tube. Centrifuge for 3 min at 20,000 $\times$ $g$, room temperature.

23. Add $200 \mu \mathrm{l}$ RNase/DNase-free $\mathrm{H}_{2} \mathrm{O}$ and incubate for $10 \mathrm{~min}$ at $70^{\circ} \mathrm{C}$. Vortex for $30 \mathrm{sec}$.

24. Transfer the gel slurry to a microcentrifuge tube filter (Costar Spin-X). Centrifuge for $3 \mathrm{~min}$ at $20,000 \times g$, room temperature.

25. Combine the three eluates per sample $(\sim 600 \mu \mathrm{l})$ and transfer to a new $1.5-\mathrm{ml}$ RNase/DNase-free non-stick tube. Add $2 \mu \mathrm{l}$ GlycoBlue $(15 \mathrm{mg} / \mathrm{ml})$ and $50 \mu \mathrm{l}$ of $3 \mathrm{M}$ sodium acetate ( $\mathrm{pH}$ 5.5). Mix well. Add $750 \mu \mathrm{l}$ isopropanol and mix. Incubate for $\geq 1 \mathrm{hr}$ at $-80^{\circ} \mathrm{C}$.

26. Recover the RNA as described in steps 13 to 15 .

27. Resuspend the RNA pellet in $22.5 \mu 1 \mathrm{RNase} / \mathrm{DNase}$-free $\mathrm{H}_{2} \mathrm{O}$.

The sample can be stored up to 3 months at $-80^{\circ} \mathrm{C}$.

Preparation and Analysis of RNA 


\section{3' RNA dephosphorylation}

RNA fragmentation by partial alkaline hydrolysis not only results in RNA molecules with a 3'-OH but also generates RNAs that contain a $3^{\prime}$-phosphate. The $3^{\prime}$-phosphate would prevent a successful DNA linker ligation, and therefore needs to be removed before ligation. This is accomplished by enzymatic dephosphorylation using T4 Polynucleotide Kinase (PNK). The T4 PNK catalyzes 3' RNA dephosphorylation in the absence of ATP. The dephosphorylation procedure described here is based on a protocol published by the Weissman lab (Ingolia, Brar, Rouskin, McGeachy, \& Weissman, 2013). The success of the enzymatic $3^{\prime}$ RNA dephosphorylation can be monitored by using the $3^{\prime}$-phosphorylated RNA control oligo oGAB11-P (Table 4.29.1, Fig. 4.29.2B, right panel).

28. Prepare the T4 PNK reaction mix as follows:

$\begin{array}{lll}\text { Component } & \text { Amount for two reactions }(\mu \mathrm{l}) & \text { Final } \\ \text { T4 PNK buffer, } 10 \times & 10 & 2 \times \\ \text { SUPERase.In }(20 \mathrm{U} / \mu \mathrm{l}) & 2 & 40 \mathrm{U} \\ \text { RNase/DNase-free } \mathrm{H}_{2} \mathrm{O} & 37.5 & \end{array}$

29. Denature $22.5 \mu \mathrm{l}$ of fragmented RNA (from step 27 ) and $22.5 \mu \mathrm{l}(0.1 \mu \mathrm{g}$ ) of oGAB11$\mathrm{P}$ control oligo for $2 \mathrm{~min}$ at $80^{\circ} \mathrm{C}$. Cool the denatured RNA on ice for $3 \mathrm{~min}$.

30. Add $25 \mu \mathrm{l} \mathrm{T4}$ PNK reaction mix (from step 28) to each tube and mix. Add $2.5 \mu 1$ T4 PNK (10 U/ $\mu \mathrm{l})$ and carefully mix.

31. Incubate the samples for $1 \mathrm{hr}$ at $37^{\circ} \mathrm{C}$ followed by $10 \mathrm{~min}$ at $75^{\circ} \mathrm{C}$ to inactivate the T4 PNK enzyme.

32. Add $450 \mu \mathrm{l}$ RNase/DNase-free $\mathrm{H}_{2} \mathrm{O}, 56 \mu \mathrm{l}$ of $3 \mathrm{M}$ sodium acetate, and $2 \mu \mathrm{l}$ of $15 \mathrm{mg} / \mathrm{ml}$ GlycoBlue, and mix. Add $600 \mu \mathrm{l}$ isopropanol and mix.

33. Precipitate the $3^{\prime}$ dephosphorylated RNA and the dephosphorylated oGAB 11 control for $\geq 1 \mathrm{hr}$ at $-20^{\circ} \mathrm{C}$.

34. Recover the RNA and the dephosphorylated oGAB11 control as described in steps 13 to 15 .

35. Resuspend pellets in $6 \mu \mathrm{l}$ pre-cooled RNase/DNase-free $\mathrm{H}_{2} \mathrm{O}$.

\section{Ligation of DNA linker-1}

36. Denature dephosphorylated RNA, the dephosphorylated oGAB11 control (from step $35)$, and the oGAB11 control $\left(1 \mu \mathrm{g}\right.$ in $6 \mu \mathrm{l}$; Table 4.29.1) for $2 \mathrm{~min}$ at $80^{\circ} \mathrm{C}$.

37. Prepare the linker ligation mix for the RNA sample, the dephosphorylated oGAB11 control, and the oGAB11 control as follows:

$\begin{array}{lll}\text { Component } & \text { Amount per reaction }(\mu \mathrm{l}) & \text { Final } \\ \text { PEG8000 }(50 \% \mathrm{v} / \mathrm{v}) & 8.0 & 20 \%(\mathrm{v} / \mathrm{v}) \\ \text { DMSO } & 2.0 & 10 \%(\mathrm{v} / \mathrm{v}) \\ \text { T4 RNA Ligase buffer }(10 \times) & 2.0 & 1 \times \\ \text { DNA linker-1 }(1 \mu \mathrm{g}) & 1.0 & \\ \text { RNA sample/oGAB11 controls } & 6.0 & 200 \mathrm{U} \\ \text { Truncated T4 RNA Ligase 2 } & 1.0\end{array}$

38. Perform the ligation reaction for $3 \mathrm{hr}$ at $37^{\circ} \mathrm{C}$. Add $0.7 \mu \mathrm{l}$ of $0.5 \mathrm{M}$ EDTA and mix to stop the ligation.

39. Add $562 \mu 1$ RNA precipitation solution and mix. Add $750 \mu l$ isopropanol and mix.

Subcellular RNA Sequencing (subRNA-seq)

4.29.10
40. Precipitate the linker-ligated RNA and the oGAB 11 controls for $\geq 1 \mathrm{hr}$ at $-20^{\circ} \mathrm{C}$.

41. Recover the RNA and the oGAB11 controls as described in steps 13 to 15 . 
42. Resuspend pellets in $10 \mu 1$ RNase/DNase-free $\mathrm{H}_{2} \mathrm{O}$.

\section{Reverse transcription}

43. Prepare the reverse transcription mix as follows:

$\begin{array}{lll}\text { Component } & \text { Amount per reaction }(\mu \mathrm{l}) & \text { Final } \\ 5 \times \text { First-Strand Buffer } & 3.3 & 1 \times \\ \text { dNTPs }(10 \mathrm{mM}) & 0.8 & 0.5 \mathrm{mM} \\ \text { RT primer oLSC007 }(10 \mu \mathrm{M}) & 0.5 & 0.3 \mu \mathrm{M}\end{array}$

44. Add $10 \mu \mathrm{l}$ of linker-ligated RNA or of the linker-ligated oGAB11 controls (step 42), mix, and incubate for $2 \mathrm{~min}$ at $80^{\circ} \mathrm{C}$. Put the sample on ice for $3 \mathrm{~min}$.

45. Add $1.3 \mu$ l SUPERase.IN/DTT mix to each tube and mix. Add $0.8 \mu 1$ of SuperScript III $(200 \mathrm{U} / \mu \mathrm{l})$ and mix.

46. Incubate the reverse transcription mixture for $30 \mathrm{~min}$ at $48^{\circ} \mathrm{C}$. Add $1.8 \mu \mathrm{l}$ of $1 \mathrm{~N}$ $\mathrm{NaOH}$, mix, and incubate for $20 \mathrm{~min}$ at $98^{\circ} \mathrm{C}$. Neutralize the reaction by adding $1.8 \mu \mathrm{l}$ of $1 \mathrm{~N} \mathrm{HCl}$, mix and put on ice.

47. Add $20 \mu 1$ of $2 \times$ TBU denaturing loading buffer to each tube and mix.

48. Also prepare the DNA control ladder by adding $1.0 \mu \mathrm{l}$ of DNA control ladder to $9 \mu \mathrm{l}$ RNase/DNase-free $\mathrm{H}_{2} \mathrm{O}$. Add $10 \mu \mathrm{l}$ of $2 \times$ TBU denaturing loading buffer and mix.

49. Denature the cDNA samples (including the oGAB11 controls) and the DNA control ladder for $3 \mathrm{~min}$ at $95^{\circ} \mathrm{C}$. Put the samples on ice for $3 \mathrm{~min}$.

50. Pre-run a $10 \%(\mathrm{w} / \mathrm{v})$ polyacrylamide TBE-urea gel at $200 \mathrm{~V}$ for $15 \mathrm{~min}$ in $1 \times \mathrm{TBE}$ buffer.

51. Separate the cDNA samples and the DNA control ladder by PAGE at $200 \mathrm{~V}$ for 65 min (also see Gallagher, 2012).

52. Stain the gel in $50 \mathrm{ml}$ of gel staining solution for $5 \mathrm{~min}$ at room temperature.

The signal intensity of the dephosphorylated oGAB11 control and of the oGAB11 control should be similar, indicating a high dephosphorylation efficiency (Fig. 4.29.2B, right panel).

53. Excise the cDNA of the original RNA sample between 85 to $160 \mathrm{nt}$ (Fig. 4.29.2B, left gel; labeled with a blue bar). Also excise the distinct band of the oGAB11 control (Fig. 4.29.2B, right gel; band is labeled with a yellow asterisk). Transfer the gel slices to two pierced (as described in step 22) 0.5-ml RNase/DNase-free tubes. Put each $0.5 \mathrm{ml}$ RNase/DNase-free tube into a $1.5 \mathrm{ml}$ RNase/DNase-free microcentrifuge tubes. Centrifuge for $3 \mathrm{~min}$ at $20,000 \times g$, room temperature.

The excision of the dephosphorylated oGAB11 control is optional.

54. Add $200 \mu \mathrm{l}$ RNase/DNase-free $\mathrm{H}_{2} \mathrm{O}$ to each tube and incubate for $10 \mathrm{~min}$ at $70^{\circ} \mathrm{C}$. Vortex for $30 \mathrm{sec}$ and transfer the gel slurry to microcentrifuge tube filters. Centrifuge $3 \mathrm{~min}$ at $20,000 \times g$, room temperature.

55. Transfer the eluate to a new 1.5-ml RNase/DNase-free non-stick tube. Add $2 \mu 1$ GlycoBlue $(15 \mathrm{mg} / \mathrm{ml})$ and $15 \mu \mathrm{l}$ of $5 \mathrm{M} \mathrm{NaCl}$, and mix.

56. Add $750 \mu \mathrm{l}$ isopropanol and mix. Precipitate cDNA for $\geq 1 \mathrm{hr}$ at $-20^{\circ} \mathrm{C}$. Centrifuge for $30 \mathrm{~min}$ at $20,000 \times g, 4^{\circ} \mathrm{C}$. Remove supernatant and wash the cDNA pellet with $750 \mu \mathrm{l}$ pre-cooled $80 \%$ (v/v) ethanol.

57. Air-dry the cDNA pellet for $10 \mathrm{~min}$ and resuspend pellet in $15 \mu 110 \mathrm{mM}$ Tris. $\mathrm{Cl}$ (pH 8.0).

Preparation and Analysis of RNA 
cDNA circularization and PCR amplification

58. Prepare the circularization mix for the cDNA sample and the oGAB11 control as follows:

$\begin{array}{lll}\text { Component } & \text { Amount per reaction }(\mu \mathrm{l}) & \text { Final } \\ \text { CircLigase } 10 \times \text { Reaction Buffer } & 2.0 & 1 \times \\ \text { ATP }(1 \mathrm{mM}) & 1.0 & 50 \mu \mathrm{M} \\ \mathrm{MnCl}_{2}(50 \mathrm{mM}) & 1.0 & 2.5 \mathrm{mM}\end{array}$

59. Add $4 \mu \mathrm{l}$ of circularization mix to $15 \mu \mathrm{l}$ of cDNA sample and the oGAB11 control (step 57) and mix. Add $1 \mu \mathrm{l}(100 \mathrm{U}$ ) of CircLigase and mix.

60. Incubate $60 \mathrm{~min}$ at $60^{\circ} \mathrm{C}$ followed by $10 \mathrm{~min}$ at $80^{\circ} \mathrm{C}$.

The circularized cDNA can be stored at $-20^{\circ} \mathrm{C}$ up to 1 year, if not proceeding immediately to the following steps.

61. Prepare PCR master mixes for four test reactions for the cDNA sample and for the oGAB11 control as follows:

Component

Phusion HF Buffer, $5 \times$

dNTPs (10 mM)

Forward primer (Illumina Index primer, $100 \mu \mathrm{M})$

oNTI231 (reverse primer, $100 \mu \mathrm{M}$ )

DNase-free $\mathrm{H}_{2} \mathrm{O}$

Phusion DNA Polymerase (2 $\mathrm{U} / \mu \mathrm{l})$
Amount for 4.5

reactions $(\mu \mathrm{l})$

18

1.8

0.45

0.45

63.9

0.9
Final

$1 \times$

$0.2 \mathrm{mM}$

$0.5 \mu \mathrm{M}$

$0.5 \mu \mathrm{M}$

$1.8 \mathrm{U}$

The oGAB11 control serves as a positive control for the PCR amplification.

62. For each reaction, place $19 \mu \mathrm{l}$ PCR master mix into a 0.2-ml PCR tube. Add $1.0 \mu 1$ circularized cDNA from the original RNA sample or from the oGAB 11 control (step 60) and mix.

63. Perform PCR test amplifications as follows:

$\begin{array}{llll}\text { Cycle number } & \begin{array}{l}\text { Denature } \\ 98^{\circ} \mathrm{C}, 30 \mathrm{sec}\end{array} & \text { Anneal } & \text { Extend } \\ 1 & 98^{\circ} \mathrm{C}, 10 \mathrm{sec} & 60^{\circ} \mathrm{C}, 10 \mathrm{sec} & 72^{\circ} \mathrm{C}, 5 \mathrm{sec}\end{array}$

Stop the PCR amplification by removing the PCR tube at the end of the extension step, typically after 6, 8, 10 and 12 rounds of amplification.

64. Add $3.4 \mu \mathrm{l} 6 \times$ DNA loading dye to each completed PCR reaction and mix. Prepare DNA control ladder. Add $1.0 \mu \mathrm{l}$ DNA control ladder to $9 \mu \mathrm{l}$ DNase-free $\mathrm{H}_{2} \mathrm{O}$. Add $2 \mu \mathrm{l}$ of $6 \times$ DNA loading dye and mix.

65. Load the PCR reactions and DNA control ladder on an $8 \%(w / v)$ TBE gel, and run at $180 \mathrm{~V}$ for $45 \mathrm{~min}$.

66. Stain the gel in $50 \mathrm{ml}$ gel staining solution for $5 \mathrm{~min}$ at room temperature. Visualize the gel and identify the optimal PCR amplification cycles for the cDNA sequencing library.

At the optimal amplification cycle, a clear band at $\sim 120$ nt is visible, whereas a DNA smear that migrates slower in an $8 \%$ TBE-gel is absent.

Subcellular RNA Sequencing (subRNA-seq)

4.29.12

67. Perform four PCR reactions per sample (not for the oGAB11 control) with the adjusted amplification cycle as described in steps 61 to 66 . 
68. Excise the PCR product from the gel and transfer the gel slice into a pierced (see step 22) 0.5-ml RNase/DNase-free tube. Put the $0.5 \mathrm{ml}$ RNase/DNase-free tube into a 1.5-ml RNase/DNase-free microcentrifuge tube. Centrifuge for $3 \mathrm{~min}$ at 20,000 $\times$ $g$, room temperature.

69. Add $670 \mu \mathrm{l}$ DNA soaking buffer and mix. Incubate in a thermomixer at room temperature overnight at $1500 \mathrm{rpm}$.

70. Transfer the gel slurry to a microcentrifuge tube filter and centrifuge for $3 \mathrm{~min}$ at $20,000 \times g$, room temperature.

71. Transfer the eluate to a new 1.5-ml RNase/DNase-free non-stick tube. Add $2 \mu 1$ GlycoBlue $(15 \mathrm{mg} / \mathrm{ml})$ and $680 \mu \mathrm{l}$ isopropanol, and mix. Precipitate the subRNAseq library for $\geq 60 \mathrm{~min}$ at $-20^{\circ} \mathrm{C}$.

72. Centrifuge for $30 \mathrm{~min}$ at $20,000 \times g, 4^{\circ} \mathrm{C}$. Discard the supernatant and wash the pellet with $750 \mu 180 \%(\mathrm{v} / \mathrm{v})$ ethanol. Air-dry pellet.

73. Resuspend the subRNA-seq library in $10 \mu 110 \mathrm{mM}$ Tris. $\mathrm{Cl}(\mathrm{pH}$ 8.0).

The subRNA-seq library can be stored at $-20^{\circ} \mathrm{C}$ up to 1 year, if not proceeding immediately.

74. Determine the quantity and quality of the subRNA-seq library by using the Qubit dsDNA HS Assay Kit and the Agilent Bioanalyzer High Sensitivity DNA Analysis Kit according to the manufacturer's instructions.

The expected concentration is 30 to $70 \mathrm{nM}$. The subRNA-seq library is ready for highthroughput sequencing on an Illumina sequencing platform using the custom sequencing primer oLSCOO6 (Table 4.29.1).

\section{REAGENTS AND SOLUTIONS}

Use RNase- and DNase-free water in all recipes and experimental protocol steps.

\section{Alkaline fragmentation solution, $2 \times$}

Composition is $100 \mathrm{mM} \mathrm{NaCO}_{3}$ (pH 9.2); for $5 \mathrm{ml}$, mix $0.6 \mathrm{ml}$ of $0.1 \mathrm{M} \mathrm{Na}_{2} \mathrm{CO}_{3}$ and $4.4 \mathrm{ml}$ of $0.1 \mathrm{M} \mathrm{NaHCO}_{3}$.Store in air-tight screw-cap tubes at room temperature for up to 4 months.

\section{Cytoplasmic lysis buffer}

$0.15 \%(\mathrm{v} / \mathrm{v}) \mathrm{NP}-40$ (Life Technologies, cat. no. 28324)

$150 \mathrm{mM} \mathrm{NaCl}$

$25 \mu \mathrm{M} \alpha$-amanitin (Sigma, cat. no. A2263)

10 U SUPERase.IN (add from 20 U/ $\mu 1$ stock; Life Technologies, cat. no. AM2696)

$1 \times$ cOmplete protease inhibitor mix, EDTA-free (Life Technologies, cat. no. 11873580001)

Prepare freshly before use and store on ice

\section{DNA soaking buffer}

For one reaction $(668 \mu \mathrm{l})$, mix:

$6.7 \mu 11 \mathrm{M}$ Tris $\cdot \mathrm{Cl}, \mathrm{pH} 8.0$ (APPENDIX 2)

$40 \mu 15 \mathrm{M} \mathrm{NaCl}$

$1.3 \mu 10.5$ M EDTA (Life Technologies, cat. no. AM9260G)

$620 \mu \mathrm{l}$ Rase/DNase-free $\mathrm{H}_{2} \mathrm{O}$ (Life Technologies, cat. no. 10977-015)

Prepare freshly before use and store at room temperature

Preparation and Analysis of RNA

4.29.13

Supplement 120 


\section{Gel staining solution}

For $50 \mathrm{ml}$ (enough for one gel): add $5 \mu \mathrm{l}$ of SYBR Gold nucleic acid gel stain $(10,000 \times$ concentrate; Life Technologies, cat. no. S-11494) to $50 \mathrm{ml}$ of $1 \times \mathrm{TBE}$ buffer (prepare from 10× TBE buffer; Life Technologies, cat. no. 15581-044). Prepare this solution freshly before use and store protected from light at room temperature.

\section{Glycerol buffer}

$20 \mathrm{mM}$ Tris. Cl, $\mathrm{pH} 8.0$ (APPENDIX 2)

$75 \mathrm{mM} \mathrm{NaCl}$

0.5 mM EDTA (Life Technologies, cat. no. AM9260G)

$50 \%(\mathrm{v} / \mathrm{v})$ glycerol

$0.85 \mathrm{mM}$ DTT

$25 \mu \mathrm{M} \alpha$-amanitin (Sigma, cat. no. A2263)

10 U SUPERase.IN (add from 20 U/ $\mu$ l stock; Life Technologies, cat. no. AM2696)

$1 \times$ Protease inhibitor mix

Prepare freshly before use and store on ice

\section{Nuclei lysis buffer}

$1 \%(\mathrm{v} / \mathrm{v}) \mathrm{NP}-40$

$20 \mathrm{mM}$ HEPES (pH 7.5)

$300 \mathrm{mM} \mathrm{NaCl}$

$1 \mathrm{M}$ urea

0.2 mM EDTA (Life Technologies, cat. no. AM9260G)

$1 \mathrm{mM}$ DTT

$25 \mu \mathrm{M} \alpha$-amanitin (Sigma, cat. no. A2263)

10 U SUPERase.IN (add from 20 U/ $\mu 1$ stock; Life Technologies, cat. no. AM2696)

$1 \times$ cOmplete protease inhibitor mix, EDTA-free (Life Technologies, cat. no. 11873580001)

Prepare freshly before use and store on ice

\section{Nuclei wash buffer}

$1 \times$ phosphate-buffered saline (PBS; Life Technologies, cat. no. 10010-023) containing:

$0.1 \%(\mathrm{v} / \mathrm{v})$ Triton X-100

$1 \mathrm{mM}$ EDTA (Life Technologies, cat. no. AM9260G)

$25 \mu \mathrm{M} \alpha$-amanitin (Sigma, cat. no. A2263)

40 U SUPERase.IN (add from 20 U/ $\mu$ l stock; Life Technologies, cat. no. AM2696)

$1 \times$ cOmplete protease inhibitor mix, EDTA-free (Life Technologies, cat. no.

11873580001)

Prepare freshly before use and store on ice

\section{RNA precipitation solution}

For one reaction $(562 \mu \mathrm{l})$ : mix $60 \mu \mathrm{l}$ of $3 \mathrm{M}$ sodium acetate, $\mathrm{pH} 5.5$ (Life Technologies, cat. no. AM9740), $2 \mu \mathrm{l}$ of GlycoBlue ( $15 \mathrm{mg} / \mathrm{ml}$; Life Technologies, cat. no. AM9515), and $500 \mu \mathrm{l}$ of RNase/DNase-free $\mathrm{H}_{2} \mathrm{O}$ (Life Technologies, cat. no. 10977-015). Prepare this solution freshly before use and store on ice.

\section{Sucrose buffer}

$10 \mathrm{mM}$ Tris. Cl, $\mathrm{pH} 7.0$ (APPENDIX 2)

$150 \mathrm{mM} \mathrm{NaCl}$

Subcellular RNA Sequencing (subRNA-seq)
$25 \%$ (w/v) sucrose (Sigma, cat. no. S0389)

$25 \mu \mathrm{M} \alpha$-amanitin (Sigma, cat. no. A2263) 
20 U SUPERase.IN (add from 20 U/ $\mu 1$ stock; Life Technologies, cat. no. AM2696)

$1 \times$ cOmplete protease inhibitor mix, EDTA-free (Life Technologies, cat. no.

11873580001)

Prepare this buffer freshly before use and store on ice

\section{SUPERase.IN/DTT mix}

For one reaction $(1.3 \mu \mathrm{l})$ : mix $0.5 \mu 1$ of SUPERase.IN (20 U/ $\mu 1$; Life Technologies, cat. no. AM2696) and $0.8 \mu \mathrm{l}$ of $0.1 \mathrm{M}$ DTT. Prepare this solution freshly before use and store on ice.

\section{COMMENTARY}

\section{Background Information}

High-throughput sequencing of subcellular RNAs has been used by the authors of this unit and others to study nascent transcription, splicing, RNA processing, and RNA transport and decay (Bhatt et al., 2012; Conrad, Marsico, Gehre, \& Ørom, 2014; Ferrari et al., 2013; Khodor et al., 2011; Mayer et al., 2015; Mondal et al., 2010; Pandya-Jones \& Black, 2009; Tilgner et al., 2012; Weber et al., 2014; Zaghlool et al., 2013). Most of these studies have focused on specific subsets of RNAs such as chromatin-associated RNAs (Khodor et al., 2011; Mondal et al., 2010). However, a detailed experimental protocol for the analysis of the identity and abundance of the full spectrum of Pol II-synthesized RNAs in different cellular compartments, ranging from unstable chromatin-associated nascent RNAs to fullyprocessed steady-state cytoplasmic RNAs, is lacking.

Here, we provide step-by-step guidance to interrogate RNAs in the chromatin, nucleoplasmic, and cytoplasmic fractions of mammalian cells. The subRNA-seq approach combines effective cell fractionation with efficient and robust sequencing library preparation, thus providing a snapshot of the subcellular distribution of RNAs at the time when cells are lysed.

The cell fractionation is based on protocols originally developed in the Schibler, Black, and Smale laboratories (Bhatt et al., 2012; Pandya-Jones \& Black, 2009; Wuarin \& Schibler, 1994), and was optimized by us to minimize cross-contamination of RNAs between the different cellular compartments and to avoid run-off transcription during sample processing (Mayer et al., 2015). Cells are lysed using the mild detergent NP-40, which keeps the nuclear membrane intact. The released nuclei are separated from the cytoplasmic fraction by centrifugation through a sucrose cushion. The nucleoplasm is separated from the chromatin in the presence of urea, NP-40, and $\mathrm{NaCl}$. This fast and effective chromatin fractionation method exploits the high stability of the Pol II transcription elongation complex, even in the presence of high salt, detergents and urea (Cai \& Luse, 1987; Wuarin $\&$ Schibler, 1994). In contrast to ionic detergents, such as Sarkosyl, urea removes most of the chromatin-associated proteins except for transcribing RNA polymerase and histone proteins (Khodor et al., 2011; Wuarin \& Schibler, 1994). The chromatin is kept in a compacted state that can be collected by low-speed centrifugation. No ultracentrifugation is required.

The DNase-treated subcellular RNAs are then applied to sequencing library preparation. The method described here is based on protocols originally developed for NET-seq (Churchman \& Weissman, 2012a; Churchman \& Weissman, 2012b; Mayer \& Churchman, 2016; Mayer et al., 2015). In contrast to the NET-seq approach, which relies on high-throughput sequencing of the $3^{\prime}$-ends of nascent transcripts, subRNA-seq sequences across entire transcripts. The subRNA-seq library generation differs in two important ways from the original NET-seq protocol:

1. RNA fragmentation is performed before DNA linker-ligation.

2. The fragmented RNAs are dephosphorylated to generate an accessible $3^{\prime}-\mathrm{OH}$ prior to the DNA linker ligation.

This library preparation method results in DNA strand-specific sequencing libraries for the cytoplasmic, nucleoplasmic, and chromatin-associated RNAs, and are ready for deep sequencing on Illumina platforms using a custom sequencing primer.

The subRNA-seq approach has been successfully used for the analysis of subcellular transcriptomes in HeLa S3 and HEK293T cells (Mayer et al., 2015). In the meantime, the authors have successfully applied the cell fractionation approach to several other mammalian cell types including K562, MOLT4, primary human foreskin fibroblasts (PadovanMerhar et al., 2015), and murine NIH/3T3 cells. Since the cell fractionation is most
Preparation and Analysis of RNA 
critical for the success of a subRNA-seq experiment, the authors expect that the protocol described here should also be applicable to any other mammalian cell type.

\section{Critical Parameters and Troubleshooting}

subRNA-seq is a quantitative genome-wide approach. This requires that each key step of the protocol works as efficiently as possible. The following steps of subRNA-seq are most critical and their success needs to be monitored.

\section{Cell fractionation}

Cell fractionation is the most critical step of the subRNA-seq protocol and needs to be as efficient as possible in order to avoid cross-contamination between the subcellular fractions. Although the cell fractionation protocol was extensively optimized (Mayer \& Churchman, 2016; Mayer et al., 2015), we recommend monitoring its success by western blotting using antibodies raised against subcellular marker proteins such as GAPDH (cytoplasmic marker), U1 snRNP70 (nucleoplasmic marker), histone 2B (chromatin marker), and transcribing RNA polymerase II (Pol II Ser2-P, chromatin marker) (Fig. 4.29.2A).

When cytoplasmic marker proteins are detected in the chromatin fraction, we recommend reducing the amount of cells per fractionation. Using more than $2 \times 10^{7}$ cells per fractionation can reduce cell lysis efficiency and thus disrupt effective fractionation. Furthermore, we recommend completely removing the supernatant after washing the cell nuclei (Basic Protocol 1, step 11).

Strong western blot signals of transcribing Pol II (Pol II Ser2-P) in the cytoplasmic fraction indicate that the treatment during cell lysis is too harsh, leading to dissociation of elongating Pol II from the chromatin. In this case, we recommend carefully reducing the amount of cell lysis buffer that is added to the cell pellet (Basic Protocol 1, step 5).

Optionally, quantitative real-time PCR can be performed to assess whether introncontaining nascent RNAs are enriched in the chromatin fraction. This can be accomplished by using primer pairs directed against selected intronic and exonic regions of well-expressed transcripts in the respective cell type of interest. Intron-containing RNAs should be enriched in the chromatin fraction, whereas intron-less, fully processed RNAs should be prevalent in the cytoplasmic fraction (Fig. 4.29.2C).

\section{3' RNA dephosphorylation}

Only RNA molecules with a $3^{\prime}-\mathrm{OH}$ will ligate with the DNA linker and be captured in the sequencing library. In order to avoid biases, and to make subRNA-seq a quantitative approach, the removal of $3^{\prime}$-phosphates should occur on $\geq 90 \%$ of the RNAs. Therefore, we recommend monitoring the success of 3'-dephosphorylation by using a 3'phosphorylated RNA control oligo (oGAB11P, Table 4.29.1 and Fig, 4.29.2B, right panel). In the case of low dephosphorylation efficiency, we recommend the following protocol adjustments: (i) increase the concentration of the T4 PNK, (ii) use a new batch of T4 PNK (different lot number), (iii) increase the T4 PNK treatment time, and (iv) decrease the amount of RNA per dephosphorylation reaction.

\section{DNA linker ligation}

Only RNA molecules that ligate to the DNA linker are captured in the final subRNA-seq library, and therefore the ligation should be as efficient as possible ( $\geq 90 \%)$. Only in this case does the final subRNA-seq library quantitatively reflect the pool of RNAs in the original sample. The ligation efficiency should be tested by using the RNA control oligo oGAB11 (Table 4.29.1 and Fig. 4.29.2). We noticed that the ligation efficiency can vary with different batches of the truncated T4 RNA Ligase 2. We recommend keeping track of the lot numbers of the ligase. Whenever the ligation efficiency is below $90 \%$, we recommend using a new batch of enzyme (different lot number). Furthermore, increasing the ligase concentration and the ligation time can enhance the ligation efficiency. We also recommend replacing components of the ligation reaction every 4 months.

\section{Anticipated Results}

The RNA yield from the cytoplasmic, nucleoplasmic, and chromatin fractions obtained from $1 \times 10^{7}$ HeLa S3 cells is $\sim 150 \mu \mathrm{g}$, $\sim 35 \mu \mathrm{g}$, and $\sim 25 \mu \mathrm{g}$, respectively. The $A_{260} / A_{280}$ ratio is $\sim 2.1$ as determined by NanoDrop spectrophotometer measurement. The efficiency of the 3 '-dephosphorylation of fragmented RNA is typically $\geq 90 \%$ as monitored by PAGE loading of the cDNA obtained from the oGAB11-P and the oGAB11 RNA control oligos (Table 4.29.1 and Fig. 4.29.2B, right panel). The efficiency of the DNA linker ligation is usually $\geq 95 \%$ as determined by PAGE using the RNA control oligo oGAB11 (Table 
4.29.1 and Fig. 4.29.2, right panel). The total yield of a typical subRNA-seq library is 20 to $30 \mathrm{ng}$, as determined by Qubit fluorometer and Bioanalyzer measurements. The average fragment length of a subRNA-seq library is $\sim 150$ nt. The RNA from the chromatin fraction is enriched for intron-containing nascent RNAs, as shown by a lower exon/intron ratio as compared to RNAs from the nucleoplasmic and cytoplasmic fractions (Fig. 4.29.2C).

\section{Time Considerations}

On day 1, cell fractionation (Basic Protocol 1, steps 1 to 16), RNA isolation (Basic Protocol 1, steps 17 to 25), DNase I digest (Basic Protocol 1, steps 26 and 27), and rRNA depletion (Basic Protocol 2, optional steps 1 to 7) are performed, which take approximately $6 \mathrm{hr}$. On day 2, the RNA is fragmented (Basic Protocol 2, steps 8 to 27) and dephosphorylated (Basic Protocol 2, steps 28 to 35). This will take approximately 5 to $6 \mathrm{hr}$. On day 3 , the DNA linker is ligated (Basic Protocol 2, steps 36 to 42) and the cDNA synthesis (Basic Protocol 2, steps 43 to 57) is conducted. This requires $\sim 5$ to $6 \mathrm{hr}$. On day 4 , the cDNA is circularized and the subRNA-seq libraries are amplified by a limited number of PCR cycles (Basic Protocol 2, steps 58 to 69). This will take $\sim 6 \mathrm{hr}$ and requires an overnight elution. On day 5, subRNA-seq library preparation is completed and the quality is monitored (Basic Protocol 2, steps 70 to 74 ). This will require $\sim 2$ to $3 \mathrm{hr}$. If the libraries pass the quality control, they are ready for sequencing on the Illumina sequencing platform.

The protocol includes many pausing points and thus can be performed in a flexible manner and according to the working habits of the experimenter.

\section{Acknowledgements}

We thank Mirjam R. Arnold for critical comments on the manuscript. We thank Julia di Iulio for help in analyzing subRNAseq data. This work was supported by U.S. National Institutes of Health National Human Genome Research Institute (NHGRI) grant R01HG007173 to L.S.C.; a Damon Runyon Dale F. Frey Award for Breakthrough Scientists (to L.S.C.); and a Burroughs Wellcome Fund Career Award at the Scientific Interface (to L.S.C.). A.M. was supported by Long-Term Postdoctoral Fellowships of the Human Frontier Science Program (HFSP) (LT000314/2013-L) and the European Molecular Biology Organization (EMBO) (ALTF858-2012).

\section{Literature Cited}

Bhatt, D. M., Pandya-Jones, A., Tong, A.-J., Barozzi, I., Lissner, M. M., Natoli, G., ... Smale, S. T. (2012). Transcript dynamics of proinflammatory genes revealed by sequence analysis of subcellular RNA fractions. Cell, 150, 279-290. doi: 10.1016/j.cell.2012.05.043.

Brueckner, F., \& Cramer, P. (2008). Structural basis of transcription inhibition by $\alpha$-amanitin and implications for RNA polymerase II translocation. Nature Structural \& Molecular Biology, 15, 811-818. doi: 10.1038/nsmb.1458.

Cai, H., \& Luse, D. S. (1987). Transcription initiation by RNA polymerase II in vitro. The Journal of Biological Chemistry, 262, 298-304.

Churchman, L. S., \& Weissman, J. S. (2012a). Nascent transcript sequencing visualizes transcription at nucleotide resolution. Nature, 469, 368-373. doi: 10.1038/nature09652.

Churchman, L. S., \& Weissman, J. S. (2012b). Native elongating transcript sequencing (NETseq). Current Protocols in Molecular Biology, 98, 4.14.1-4.14.17. doi: 10.1002/0471142727 .mb0414s98.

Conrad, T., Marsico, A., Gehre, M., \& Ørom, U. A. (2014). Microprocessor activity controls differential miRNA biogenesis in vivo. Cell Reports, 9, 542-554. doi: 10.1016/j.celrep.2014.09 .007 .

Djebali, S., Davis, C. A., Merkel, A., Dobin, A., Lassmann, T., Mortazavi, A., ... Gingeras, T. R. (2013). Landscape of transcription in human cells. Nature, 488, 101-108.

Ferrari, F., Plachetka, A., Alekseyenko, A. A., Jung, Y. L., Ozsolak, F., Kharchenko, P. V., ... Kuroda, M. I. (2013). “Jump start and gain" model for dosage compensation in drosophila based on direct sequencing of nascent transcripts. Cell Reports, 5, 629-636. doi: 10.1016/j.celrep.2013.09.037.

Gallagher, S. R. (2012). One-dimensional SDS gel electrophoresis of proteins. Current Protocols in Molecular Biology, 97, 10.2A.1-10.2A.44. doi: 10.1002/0471142727.mb1002as97.

Ingolia, N. T., Brar, G. A., Rouskin, S., McGeachy, A. M., \& Weissman, J. S. (2013). Genomewide annotation and quantitation of translation by ribosome profiling. Current Protocols in Molecular Biology, 103, 4.18:4.18.1-4.18.19. doi: 10.1002/0471142727.mb0418s103.

Ingolia, N. T., Brar, G. A., Rouskin, S., McGeachy, A. M., \& Weissman, J. S. (2012). The ribosome profiling strategy for monitoring translation in vivo by deep sequencing of ribosome-protected mRNA fragments. Nature Protocols, 7, 15341550. doi: 10.1038/nprot.2012.086.

Jensen, T. H., Jacquier, A., \& Libri, D. (2013). Dealing with pervasive transcription. Molecular Cell, 52, 473-484. doi: 10.1016/ j.molcel.2013.10.032.

Jonkers, I., \& Lis, J. T. (2015). Getting up to speed with transcription elongation by RNA polymerase II. Nature Reviews Molecular Cell Biology, 16, 167-177. doi: 10.1038/nrm3953.
Preparation and Analysis of RNA 
Khodor, Y. L., Rodriguez, J., Abruzzi, K. C., Tang, C. H. A., Marr, M. T., \& Rosbash, M. (2011). Nascent-seq indicates widespread cotranscriptional pre-mRNA splicing in Drosophila. Genes \& Development, 25, 2502-2512. doi: 10.1101/gad.178962.111.

Kilchert, C., Wittmann, S., \& Vasiljeva, L. (2016). The regulation and functions of the nuclear RNA exosome complex. Nature Reviews Molecular Cell Biology, 17, 227-239. doi: 10.1038/nrm.2015.15.

Lindell, T. J., Weinberg, F., Morris, P. W., Roeder, R. G., \& Rutter, W. J. (1970). Specific inhibition of nuclear RNA polymerase II by alpha-amanitin. Science, 170, 447-449. doi: 10.1126/science.170.3956.447.

Mayer, A., \& Churchman, L. S. (2016). Genomewide profiling of RNA polymerase transcription at nucleotide resolution in human cells with native elongating transcript sequencing. Nature Protocols, 11, 813-833. doi: 10.1038/nprot.2016.047.

Mayer, A., Di Iulio, J., Maleri, S., Eser, U., Vierstra, J., Reynolds, A., ... Churchman, L. S. (2015). Native elongating transcript sequencing reveals human transcriptional activity at nucleotide resolution. Cell, 161, 541-554. doi: 10.1016/j.cell.2015.03.010.

Meinel, D. M., \& Sträßer, K. (2015). Cotranscriptional mRNP formation is coordinated within a molecular mRNP packaging station in S. cerevisiae. BioEssays, 37, 666-677. doi: 10.1002/bies.201400220.

Mondal, T., Rasmussen, M., Pandey, G. K., Isaksson, A., \& Kanduri, C. (2010). Characterization of the RNA content of chromatin. Genome Research, 20, 899-907. doi: 10.1101/gr.103473.109.

Ni, D., Xu, P., and Gallagher, S. (2016). Immunoblotting and immunodetection. Current Protocols Molecular Biology, 114, 10.8.110.8.37. doi: 10.1002/0471142727.mb1008s 114

Oeffinger, M., \& Zenklusen, D. (2012). To the pore and through the pore: a story of mRNA export kinetics. Biochimica et Biophysica Acta, 1819, 494-506.

Padovan-Merhar, O., Nair, G. P., Biaesch, A. G., Mayer, A., Scarfone, S., Foley, S. W., ... Raj, A. (2015). Single mammalian cells compensate for differences in cellular volume and DNA copy number through independent global transcriptional mechanisms. Molecular Cell, 58, 339352. doi: 10.1016/j.molcel.2015.03.005.

Pandya-Jones, A., \& Black, D. L. (2009). Cotranscriptional splicing of constitutive and alternative exons. RNA, 15, 1896-1908. doi: 10.1261/rna.1714509.

Pelechano, V., \& Steinmetz, L. M. (2013). Gene regulation by antisense transcription. Nature Reviews Genetics, 14, 880-893. doi: 10.1038/nrg3594.

Phelan, K., \& May, K. M. (2017). Mammalian cell tissue culture techniques. Currrent Protocols in Molecular Biology, 117, A.3F.1-A.3F.23. doi: 10.1002/cpmb.31.

Tilgner, H., Knowles, D. G., Johnson, R., Davis, C. A., Chakrabortty, S., Djebali, S., ... Guigo, R. (2012). Deep sequencing of subcellular RNA fractions shows splicing to be predominantly co-transcriptional in the human genome but inefficient for IncRNAs. Genome Research, 22, 1616-1625. doi: 10.1101/gr.134445.111.

Venkatesh, S., \& Workman, J. L. (2015). Histone exchange, chromatin structure and the regulation of transcription. Nature Reviews Molecular Cell Biology, 16, 1-12. doi: 10.1038/nrm3941.

Wang, Z., Gerstein, M., \& Snyder, M. (2009). RNA-Seq: A revolutionary tool for transcriptomics. Nature Reviews Genetics, 10, 57-63. doi: $10.1038 / \mathrm{nrg} 2484$.

Weber, C. M., Ramachandran, S., \& Henikoff, S. (2014). Nucleosomes are context-specific, H2A.Z-modulated barriers to RNA polymerase. Molecular Cell, 53, 819-830. doi: 10.1016/j.molcel.2014.02.014.

Wickramasinghe, V. O., \& Laskey, R. A. (2015). Control of mammalian gene expression by selective mRNA export. Nature Reviews Molecular Cell Biology, 16, 431-442. doi: 10.1038/nrm4010.

Wuarin, J., \& Schibler, U. (1994). Physical isolation of nascent RNA chains transcribed by RNA polymerase II: Evidence for cotranscriptional splicing. Molecular and Cellular Biology, 14, 7219-7225. doi: 10.1128/MCB.14.11.7219.

Zaghlool, A., Ameur, A., Nyberg, L., Halvardson, J., Grabherr, M., Cavelier, L., \& Feuk, L. (2013). Efficient cellular fractionation improves RNA sequencing analysis of mature and nascent transcripts from human tissues. BMC Biotechnology, 13, 99. doi: 10.1186/1472-6750-13-99.

\section{Subcellular RNA Sequencing (subRNA-seq)}

